\title{
OS ANTECEDENTES DA DECLARAÇÃO DOS DIREITOS DE 1789 E SUA EVOLUÇÃO *
}

\begin{abstract}
Nilton Bussi
Sumário: Introdução. Precedentes: Ciclo Inglês; Aspectos iniciais norte-americanos; Peculiaridades diferenciais do constitucionalismo anglo-americano e francês; $\mathrm{O}$ movimento revolucionário francês; das Conseqüências. Anotações sobre a Teoria Constitucional Russa. Conclusão.
\end{abstract}

\section{1 - INTRODUÇÃO}

A história das Declarações dos Direitos pode tomar como ponto de partida, a viagem a bordo do navio "Mayflower" que levava os peregrinos para a nova terra, a busca de liberdade religiosa e porteriormente política em que se converteu a conquista da América.

Ali as "convenantes" dos peregrinos pode estabelecer os primeiros princípios que deveriam nortear os seus futuros passos quando em terra.

Sem dúvida, foi o Estado da Virginia, que teve a grande honra de haver sancionado já em 12 de junho de 1776, a primeira declaração de direitos de caráter humanista que se conhece, a rigor, na história humana.

Ela como autêntico "bill of rights" de autoria de Jorge Mason e que serviu de modelo para a dos demais Estados. dos.

Alguns pontos capitais dessa declaração podem ser assinala-

Os representantes do bom povo de Virginia, reunidos em livre convenção (assembléia geral e livre) proclamavam:
"I - Que todos os homens são, por natureza, igualmente livres e independentes, e têm certos direitos inatos" e que não podem ser privados dos seguintes direitos: "o gozo da vida e da liberdade com os meios de adquirir e de possuir a propriedade e de buscar e obter felicidade e segurança".

\footnotetext{
- Trabalho apresentado à Disciplina de Direito Consțitucional do Curso de Mestrado da Faculdade de Direito do Setor de Ciências Jurídicas da UFPR.
} 
No parágrafo II: "Que todo poder é inerente ao povo e, conseqüentemente, dele procede; que os magistrados são seus mandatários e seus servidores, e em qualquer momento, perante ele responsáveis".

No inciso III fixava novos princípios:

"Que o governo é instituído, ou deveria sê-lo, para proveito comum, proteção e segurança do povo, nação ou. comunidade; que de todas as formas e modos de governo esta é a melhor, a mais capaz de produzir maior felicidade e segurança, e a que está mais eficazmente assegurada contra o perigo de um mau governo; e que se um governo se mostra inadequado ou é contrário a tais princípios, a maioria da comunidade tem o direito indiscutível, inalienável e irrevogável de reformá-lo, alterá-lo ou aboli-lo da maneira considerada mais condizente com o bem público".

Seguindo a doutrina de Montesquieu, afirmava o princípio da independência dos poderes legislativo, executivo e judiciário na cláusula $\mathrm{V}$, nela também se impondo o direito do povo deles participar, pois de tempos em tempos os eleitos devem retornar:

"à sua condição de particulares e suas vagas se preencham mediante eleiç̃̃es periódicas, certas e regulares, nas quais possam voltar a se eleger todos ou parte dos antigos membros (dos mencionados poderes), segunđo disponham as leis".

Na cláusula VI que todos tinham direito ao sufrágio, sendo as eleições livres, fixando ainda esta cláusula que:

"e não possem ser submetidos à tributação nem privados de sua propriedade por razões de utilidade pública sem seu consentimento, ou o de seus representantes assim eleitos, nem estejam obrigados por lei alguma à que, da mesma forma, não hajam consentido para o bem público".

Na cláusula VII previa-se que:

"Toda faculdade de suspender as leis ou a execução destas por qualquer autoridade, sem consentimento dos representantes do povo, é prejudicial aos direitos deste e não deve exercer-se". 
A cláusula XII de fundamental significado democrático estabelecia:

"Que a liberdade de imprensa é um dos grandes baluartes da liberdade, não podendo ser restringida jamais, a não ser por governos despóticos".

No tocante aos direitos e garantias individuais no campo processual, estabelecia que toda investigação criminal dava a homem o direito de averiguar a causa e a natureza da acusação, de ser acareado com os acusadores e testemunhas, que a livre produção da prova era ao lado de um julgamento rápido por um tribunal imparcial composto de doze homens de sua comunidade, sem 0 que não pode ser considerado culpado e que ninguém poderia ser compelido a declarar contra si próprio, nem ser privado da liberdade a não ser conforme as leis do país ou por julgamento de seus pares.

Pioneiramente dizia que a milícia, na cláusula XII, bem regulamentada e integrada por pessoas adestradas nas armas, constitui defesa natural e segura de um Estado livre; que deveriam ser evitados em tempo de paz, como perigosos para a liberdade e fixava a regra sempre observada de que:

"as forças armadas estarão estritamente subordinadas ao poder civil e sob o comando deste”.

Finalmente assegurava que a religião e seus deveres, para com o Criador, somente podem ser dirigidos pela razão e convicção, não pela força ou pela violência, consequientemente estabelecia que:

"todos os homens têm igual direito ao livre exercício da religião, de acordo com o que dita sua consciência, e que é dever recíproco de todos praticar a paciência, o amor e a caridade crisiã para com o próximo".

Como se vê, a Declaração de Virginia consagrou os princípios e formulações até então discutidos e sonhados, compilando toda a doutrina então existente, apresentando claros enunciados que vieram a influir poderosamente nas Constituições dos outros Estados norte-americanos, até mesmo na própria Declaração da Independência dos Estados Unidos e na Declaração dos Direitos do Homem e do Cidadão da França, e por isso, é amplamente reconhecida pelos constitucionalistas come um dos sustentáculos do moderno direito constitucional. 
Quando por ocasião da independência dos Estados Unidos, assinada em 04 de julho de 1776, a ata redigida por Thomas Jefferson,e que emancipava as 13 Colônias da Inglaterra nela foram consignados vários princípios institucionais já constantes da Declaração Virginiana.

Como se destaca após haverem apresentado as razões da indeperdência, declaravam ainda que todos os homens nascem iguais e que foram dotados pelo Criador de direitos inalienáveis, entre os quais: a vida, a liberdade e a procura da felicidade; que são estabelecidos governos para assegurar e garantir esses direitos e que o poder dos governantes emana do povo.

Sempre que a forma de governo seja destruidora desses fins têm os povos o direito de mudá-los, aboli-los e de estabelecer um novo governo, baseado naqueles princípios fundamentais e se organizando de forma mais adequada para garantir a segurança e o bem-estar.

Se reconhece airda ao povo o direito de resistência à opressão, porém, como "ultima ratio" à prepotência e aos absolutismos de qualquer forma.

\section{2 - PRECEDENTES}

\section{1 - Ciclo Inglês}

Os historiadores destacam que não havia uma oposição à monarquia britânica, porque a própria estruturação inglesa gozava de grande prestígio entre pensadores e homens públicos de toda a Europa e os que vieram para a América sabiam disso.

O desenvolvimento do espírito revolucionário é atribuído aos problemas fiscais, notadamente a taxação do chá, além dos escritos de Thomas Paine (Los Derechos del Hombre) que era uma espécie de cavaleiro andante da liberdade e que se opunha à famosa frase de Franklin:

"onde há liberdade ali cstá minha pátria",

dizendo o panfletista:

"onde não há liberdado, ali está a minha pátria".

Thomas Paine entendia que os direitos pertencem aos homens pelo fato de sua simples existência e por isso todos são iguais em direitos; aduzindo ainda, seu horror às velhas formas de governo, pregando:

"Todo poder delegado é confiança e todo poder arrogante é usurpação. Quem quer ver segura a sua liberdade deve garanti-la, ainda aue seu inimigo seja oprimido; porque quem viola este ciever, estabelece um exemplo que alcançará a ele mesmo". 
Deve-se sobretudo a este escritor o cuidado e a característica de se haver preocupado extraordinariamente com o cidadão comum, voltando-se para o povo, como a fonte única e exclusiva de inspiração do poder.

Como ensina a história, a última parte do século XVIII foi um período fecundo de grave agitação social, fermentando as idéias sobre o homem, seu valor e dignidade, como ser humano que é, voltando-se para os valores morais na busca da liberdade, segurança e felicidade em seus significados mais amplos.

Como assinala o notável Pinto Ferreira, o ciclo constitucional inglês surge com sua expressão máxima na "Magna Carta" de 1215, derivada de coliflitos entre o rei João sem Terra, contra os barões, existindo a respeito dela profundos debates, alguns negando caráter político ao documento. Todavia, o constitucionalismo brasileiro, baseando-se nos estudos de Willian Anson (Loi et Pratique Constitucionelle de L'Anglaterre), escreve:

“... pois é certo afirmar-se que a Magna Carta é uma lei constitucional um dos noucos documentos escritos do regime político inglês, lei constitucional imperfeita, modelada segundo a técnica legislativa da época, mas com grau de super-legalidade empírica incontestável”. (Pág. 96).

Seguem-se a "Petition of Rights" de 1629 e mais tarde com a Revolução de 1648 prosseguiu a polêmica entre a burguesia e a nobreza, surgindo a República de Cromwell e com ela no dizer de Paul Esmein (Elements de Droit Constitutionnel Français):

"a primeira Constituição escrita, nacional e limitativa, que fez sua aparição no mundo" (Vol. II, pág. 616, Paris, 1927).

Segue-se o célebre "Instruments of Government" promulgado por Cromwell em 16 de dezembro de 1652 em 42 artigos, que foi precedido em importância pelo "Agreement of the péople" de 1647, sendo pois, os precursores do movimento constitucionalista ampliado pelos americanos do norte.

O coroamento do processo histórico do constitucionalismo britânico teve o seu ápice com c "Habeas Corpus Act" de 1679 e posteriormente o "Bíll of Rights", ou Declaração dos Direitos de 13 de fevereiro de 1688, votada por ambas as Câmaras (dos Lordes e dos Comuns) que veio a estabelecer fortes limitações constitucionais ao absolutismo da monarquia. 


\section{2 - Aspectos iniciais norte-americanos}

A situação estrutural nas colônias americanas era interessante, em algumas o poder executivo, confiado a um governador designado pela Coroa, em 8 (oito) provincias reais ou eleito pelo povo em algumas delas ou simplesmente designados pelos proprietários como era o caso de Maryland e Pensilvânia.

O legislativo era exercido por duas Câmaras, a baixa eleita pelo povo e a alta formada por membros nomeados pela Corna ou por recomendação do executivo colonial cu designada pelos proprietários, funcionavam como conselhos do governador.

Algumas situações inusitadas se criavam, e devido ao tempo eram solucionadas conforme os interesses locais e às vezes prevaleciam, face à distância da metrópole.

O judiciário era composto por tribunais locais e intermediários, existindo uma alta corte de justiça para a qual se podia apelar as "Privy Council" na Inglaterra.

Esse conselho privado foi, na verdade, o embrião da suprema corte.

Com a declaração da independência, juntaram-se as Colônias no ano seguinte, formando a Confederação, com os "Artigos da Confederação e União Perpétua", promulgando-se as Constituições Estaduais, que seguiam as idéias predominantes de Locke, Montesauieu e Paine, versando sobre os direitos naturais, soberania popular, sistema de freios e contrapesos refletindo a legislação o pensamento político de então.

Em 17 de setembro de 1787 em Filadélfia, foi proclamada a Constituição, face ao notável trabalho desenvolvido pelos patriarcas Franklin, Washington, Hamilton e Madison; pela Constituição, a antiga Confederação transformou-se em Estado Federal e mesmo assim não possuia declaração de direitos.

Só em 1789 foram acrescertados 10 artigos à Constituição Americana, como uma declaração d€ direitos contida na própria Carta, o chamado "preço da ratificação".

Por isso é que no seu famoso estudo Jellineck anotava:

"Na América é donde se há de buscar a origem de nossas atuais constituições escritas, e por isso se deve prestar uma maior atenção à mesma. A Revolução Francesa aceita a idéia americana e da França ela se estende aos demais Estados Europeus". 


\section{3 - Peculiaridades diferenciais do constitucionalismo anglo-}

americano e francês

$\mathrm{Na}$ América do Norte os "bill ou rights" são havidos e reconhecidos como direitos que correspondem ao homem enquanto ser humano e como tais anteriores e superiores ao próprio Estado, não são concessões, mas limitações ao poder público estabelecidos pela soberania popular.

Enquanto os atos ingleses revelam a prática de um direito consuetudinário, direitos que são consagrados mas que são uma reação à sistemática violação feita pelo poder soberano monárquico.

Vale registrar que Paolo Biscaretti di Ruffia (Lo Stato Demo. crático Moderno nella Legislazione constituzionale - Milão, 1946, págs. 655/656), já destacava que as conquistas britânicas deveriam ser transmitidas como um patrimônio de pai para filho, face ao seu valor e para manter o vigor das instituições.

Acresce ainda o mesmo Paolo B. di Ruffia, que as insituições inglesas que inspiraram os norte-americanos são, na verdade, um estágio intermediário entre a formulação consuetudinária britâvica de caráter prático e as profundas digressões filosóficas francesas que fervilhavam naquela época, indo desaguar na monumental "Déclaração dos Direitos e do Cidadão", e que se constitui num "esquemático catecismo político-social".

O notável Sanchez Viamonte, observa que os norte-americanos consagraram os direitos do homem no constitucionalismo e no direito positivo sem dar-lhes um fundamento filosófico e racional.

Esses direitos do homem eram tidos como verdades irrefutáveis e ninguém se preocupou $€ m$ discutir-lhes a essência com profundidade.

Essa tarefa já existia na França antes mesmo da independência americana e constitui na opinião de doutrinadores a grande diferença entre as respectivas Declarações, porque a atitude americana é simplista e prática enquanto a francesa é profundamente ideológica e racional.

Raymond G. Gettel (Histöria das idéias políticas) destaca que a prática constitucional americana decorre ainda de características peculiares, como a ausência de modalidades e costumes feudais e principalmente do sistema congregacional na organização eclesiástica então adotada.

Finalmente a existência de um constitucionalismo sancionado por representantes do povo reunidos exclusivamente para esse fim, a declaração dos direitos do homem anteriores e superiores ao Estado e aos limites da autoridade governamental, são pres- 
supostos do Direito Constitucional Moderno. Locke e Montesquieu, num plano bem superior e Rousseau em menor grau, influenciaram os norte-americanos, porém, Jean Jacques Rousseau predominou entre os franceses.

Essa influência marca um debate interessante.

Autores assinalayam como Linares Quintana a transcendência histórico-política universal que alcançou a Revolução Francesa, que chega a obscurecer ao intenso brilho do movimento americano, sendo que é indiscutível que no aspecto institucional houve preponderância constitucional e do movimento americano.

Ambas apresentam, em comum, sua raiz ideológica no vasto movimento filosófico e político que surgiu no século XVII e início do século XVIII.

Carlos Sanchez Viamonte publicou um profundo estudo sobre o tema, intitulado "A Revolução Norte-americana e a Revolução Francesa", chegando à seguinte conclusão:

"A Revolução Francesa adotou a sistemática da emancipação norte-americaia, porém, criou a mística do ideal democrático de perfeição social indefinida e contínua. Pisando sobre o cimento doutrinário da soberania social construída em definitivo por Rousseau, procurou assegurar com técnica saxînica o exercício da liberdade individual. Se concilia desse modo uma contradição. Os termos opostos soberania e direitos do homem se enla.çam em cordial abraço". (Pág. 2).

G. Jellineck, analisando a "Declaração de 1789 não teve em Rousseau, mas na Declaração da Independência dos Estados Unidos de 1776, e nos demais "bill of rigts" americanos; e que estes foram inspirados pelo luteranismo e pelo individualismo germânico transposto desde o direito romano, segundo sua linha histórica.

Tal estudo e conclusão mereceu ampla refutação de E. Boutmy em "La declaration des droits de l'homme et du citoyen et $M$. Jellineck" (in Anales des Sciences Politiques, Paris, 1902, págs. $415 / 443)$; nesse traba!ho mostra-se de forma clara e forte a notável influência dos trabalhos de Jean Jacques Rousseau sobre a declaração francesa e se faz uma pertinaz oposição aos escritos e conclusões do jurista alemão.

M. Hauriou, em "Princípios de Derecho Público y Constitucional" (pág. 97), escreve que a fonte comum inspiradora das Declarações de Direito do Homem, e a sua enumeração deve ser encontrada na Escola de Direito Natural; na Doutrina do Contrato Social, ainda nos escritos de Locke, cujas idéias, acrescenta, o jurista inglês Blackstone transformou em regras jurídicas, apresentando a enumeração das principais liberdades individuais e que 
nelas se vê a origem imediata da Declaração de Direitos do Estado de Virgínia; indo mais além chega a apontar os fundamentos do Cristianismo, como sendo o inascedouro da limitação da soberania do Estado e a valoração dos direitos do homem como ser ontológico.

Muito interessantes são as palavras de Hamilton, sobre a Declaração de Direitos, sabendo-se que ele interveio na redação da Carta Constitucional Americana, pois dizia que:

“... as declarações de direitos são originariamente pactos entre reis e súditos, diminuição das prerrogativas reais em favor de seus súditos, reservas de direito que não abandonavam ao príncipe. Dessa índole é a Magna Carta arrancada pelos barões, espadas em punho ao Rei João";

continua dizendo que tais conquistas não se assemelhavam às Constituições, porque estas emanavam do povo através de seus representantes, mais adiante, opina que o "Preâmbulo" constitui.

"um reconhecimento de direitos populares que ficariam melhor em um tratado de ética do que na Constituição de um governo".

Apesar dessa oposiçâo, a técnica que se empregou foi a de assegurar por meio de emendas que vieram a assegurar e a preseivar as liberdades e os direitos, por esse caminho de 1789 a 1791 se sancionaram as dez (10) primeiras emendas à Constituição que se constituíram em legítimos e autênticos "bill of rights".

\section{4 - O movimento revolucionário francês}

Afirma com propriedade o consagrado Carl Schmitt (Teoria de La Constitucion - págs. 57/58) que:

“... na Revol'xção Francesa de 1789 surge a Constituição moderna, mista de elementos liberais e democráticos. Seu suposto mental é a teoria do Poder Constituinte. A teoria do Estado da Revolução Francesa passa a ser assim uma fonte capital não só para a dogmática política de todo o tempo seguinte, senão também par̃a a construção juridica de caráter positivo da moderna teoria da Constituição".

$\mathrm{Na}$ análise do pensamento de Carl Schmitt sobre a obra inigualável do povo francês destacam ainda os mestres a distinção por ele feita de que os franceses se constituíram em sujeitos destinatários do Poder Constituinte e conscientes de sua capacitação política sob o império da Constituição que emana do povo, num 
Estado tipicamente burguês, construíram e incluíram o exercício de limites e freios e contrapesos à própria administração do Estado.

Outros autores empolgados pela ciência do Direito Constitucional que florescia na França, a erigem como marcos modernos do processo de civilização humana - obra de verdadeiro iluminismo cuitural - destacando, a Constituição para a teoria do moderno constitucionalismo de um lado e seu Código Civil, para a regulação dos direitos privados de outro, acrescentando um novo significado ao mundo jurídico e transparecendo nova motivação para o simbolismo de se chamar a cidade de Paris, sua capital, como cidade "luz do mundo" pelo renascimento do pensamento filósofico e jurídico.

O principal oráculo da Revolução Francesa foi o padre Emmanuel Joseph Sieyès com o surgimento de seu opúsculo intitulado: “Qu'est-ce que le tiers État?", colocando três questões primaciais:

Que é o terceiro Estado? respondendo tudo;

Que tem sido até ag:ra na ordem política?

Responde dizendo nada;

O que pede? responde: chegar a ser alguma coisa.

Dentro da classificação do padre francês, havia três classes ao seu tempo, claramente distintas: primeiro o clero, segundo a nobreza, e terceiro o povo.

Esses estamentos sociais eram rígidos e predominantes antes da Revolução Francesa, sendo que mais tarde, após o advento dessas idéias políticas que encontravam sua base primeira na Escola do Direito Natural, a igualdade começou a propiciar ligeira alteração dos quadros, até mesmo no exército onde a oficialidade só podia ser alcançada pelos nobres, o que foi modificado pela visão política de Napoleão.

$\mathrm{Na}$ época da revolução de 1789 a França estava no tempo da vassalagem que escravizava o homem à terra, o imposto feudál, as senhorias, as jurisdições eclesiásticas, o controle rígido da imprensa, que importaram por exemplo a polemistas famosos como Mirabeau, que sofreu o exílio e a prisão pelos seus escritos, notadamente o "Ensaio sobre o Despotismo", em que atacava a Monarquia e suas deturpações.

As prisões eram incontestáveis e a figura de Salpetriere e da Bastilha predominavam além de outras casas prisionais sinistras como a prisão da Ilha de Ré e If. Neste quadro desalentador, as "Declarações de Direito", verdadeiro anseio popular, tem nelas o sistema de apoio e arnparo da likerdade individual, e de limitação ao poder público, prevendo a verdadeira razão de ser do constitu cionalismo. 
O notável abade francês de Chartres, anteviu a essência do constitucionalismo ao estabelecer a primazia do Poder Constituinte e sua teoria constitucional, colocando que esse poder originário tem como sua verdadeira fonte o povo.

Baseou-se fundamentalmente nas doutrinas de Jean Jacques Rousseau, no seu Contrato Social, pois o homem nasce livre, é portanto anterior ao Estado, seu naturalismo indica que há direitos naturais decorrentes da própria condição do ser humano enquanto considerado como tal, todos os homens nascem livres e têm absoluta igualdade para a procura da felicidade, já antevendo a máxima da Revolução Francesa da "Liberté, fraternité et igualité", como a "summa divisio" da ração.

De Montesquieu adotou para a organização do Estado e quebra do poder monárquico, o princípio da divisão dos poderes, em executivo, legislativo e judiciário.

Entendia que a Constituição votada por uma Assembléia Constituinte, formada por deiegados ou mandatários do povo, deveria estabelecer a organização do Estado, suas funções, os órgãos encarregados da atuação da vontade estatal e principalmente as liberdades individuais e os meios de tornarem-nas realidade.

Sendo a Constituição obra cio Poder Constituinte, votada por uma Assembléia para tal especialmente convocada, e sendo o povo o detentor natural do poder constituinte, somente por outra Constituição se poderia modificar totalmente essa Carta, ou parcialmente conforme ela mesma o estabelecesse.

A contribuição de Sieyès, classificada por alguns como a teoria racional ideal, repousa em quatro (04) pilares básicos:

a) o princípio da liberdade sobre o qual se estrutura $\lambda$ nação;

b) a nação ccmo ente de direito natural;

c) sistema de representação popular (delegados ou mandatários):

d) criação do poder Constituinte para estabelecer a Constituição, que deveria ser escrita.

Com efeito, em 26 de agosto de 1789 a Assembléia Nacional francesa discutiu e fez aprovar a célebre "Declaração dos Direitos do Homem e do Cidadão", marco de humanismo e civilização, que teve enorme repercussão e se irradiou pela Europa toda, marcando profundamente as linhas mestras do direito constitucional que viria a ser editado dali para frente.

O seu preâmbulo, tantas vezes elogiado, vale por si próprio merecendo integral transcrição: 
"Os representantes do povo francês, reunidos em Assem-. bléia Nacional, tendo em vista que a ignorância, o esquecimento ou o desprezo dos direitos do homem são as únicas causas dos males públicos e da corrupção dos Governos, resolveram declarar solenemente os direitos naturais, inalienáveis e sagrados do homem, a fim de que esta declaração, sempre presente em todos os membros do corpo social, lhes lembre permanentemente seús direitos e seus deveres, a fim de que os ato do Poder Legislativo e do Poder Executivo, podendo ser a qualquer momento comparados com a finalidade de toda a instituição política, sejam por isso mais respeitados; a fim de que as reivindicações dos cidadãos, doravante fundadas em princípios simples e incontestáveis, se dirijam sempre à conservação da Constituição e à felicidade geral".

Suas palavras são marcadas pela característica da perenidade, sempre presente e não perdendo sua atualidade, mesmo nos dias atuais.

Dalmo de Abreu Dallari, em apropriado estudo sobre as declarações de direitos, em seu valioso livro "Elementos de Teoria Geral do Estado" (São Paulo, Saraiva, 1972, págs. 180/182), assinala que essa declaração francesa tem sentido nitidamente individualista e chega a compará-ia com a de Virginia que diz ser de sentido de maior profundidade social, e mais abrangente.

Mas não resta a menor dúvida quanto ao caráter de universalidade e eternidade, marcas perenes que acompanham o homem na sua contínua evolução.

Opondo limites ao absolutismo do Estado, à prepotência contra a liberdade do cidadão e à sua plenitude enquanto ser, a declaração francesa repete o que havia de universal a respeito desses direitos inalienáveis, imprescritíveis e irrenunciáveis, merecendo, dentre seus dezessete (17) artigos, referências claras, ao direito da mais ampla liberdade e suas conseqüências como a liberdade de associação política e religiosa, a igualdade e a fraternidade, ressaltando-se como predominante 0 art. 16 de sua estrutura, que asseverava:

“Art. 16. A sociedade em que não esteja assegurada a garantia dos direitos nem estabelecida a separação dos poderes não tem Constituição". 
Aqui, uma regra de profunda sabedoria e previsão marca o constitucionalismo moderno, com garantias de direitos rigorosamente estabelecidos, seus mecanismos de proteção, a divisão dos poderes e sua independência, além da necessária e imprescindível harmonia, como características da Lei Maior que a tudo se sobrepõe.

A declaração francesa é, sem dúvida, um marco da história universal das liberdades fundamentais do ser humano.

\subsection{Das Conseqüências}

Assim o fermento da idéia de uma Constituição escrita, difundiu-se rapidamente, porque representava, induvidosamente um grande progresso, e marcava o desenvolvimento de um pensamento libertador do homem na sua contínua busca do aperfeiçoamento.

Essa difusão, constante e avassaladora, levou de roldão seus opositores, que pretendiam a restauração da Monarquia e do Absolutismo, em favor dos direitos da pesisoa hurnana como tal considerada, e aperfeiçoava o exercicio do direito político de liberdade.

Quebrava-se a antiga parêmia do "Omnia potestas a Deo" que pretendia um direito monárquico cujos poderes eram oriundos da divindidade.

Mas o notável Manoel G. Ferreira Filho recolhe uma advertência, em relação ao constitucionalismo, que se inaugura com o surgimento do moderno direito constitucional, dentro das premissas estabelecidas pelo abade Sieyès, de que: "Constitutions are not made, they grow" (in "O Poder Constituinte"); o sentido de sua existência deve tanto quanto possível coresponder à realidade, traduzindo-se numa prática constante e aperfeiçoadora.

\section{ANOTAÇÕES SOBRE A TEORIA CONSTITUCIONAL RUSSA}

Diferentemente das declarações de direitos americana e francesa, o movimento russo apresenta modificações substanciais.

Como se sabe, o sistema político russo está baseado na tradicional afirmação da ditadura do proletariado, que na prática constitui o proletariado como titular do poder político retirando-o da até então burguesia cuja classe é a sua oposição.

Na luta de classes, o proletariado há de ser a maior parte da população, superior a toda norma jurídica, isto porque nele proletariado hão de estar os assalariados, sejam da indústria, camponeses e outros trabalhadores.

$\mathrm{Na}$ luta de classes que se estabelece na sociedade, evidentemente haverá sempre uma classe dominadora, e esta há de ser a proletária. 
A Revolução Russa, que se deu em 1917, teve desdobramentos importantes, promovendo a visão social da economia, pois Georges Gurvitch chegou a denominar de Estado Econômico total à organização russa.

Em 06 de janeiro de 1918, o terceiro congresso pan-russo, hos trabalhos da Assembléia Constituinte Russa, aprovou a "Declaração dos direitos do povo trabalhador e explorado", redigida por Lenin, que principiava por estabelecer que na Rússia era constituída uma República dos sovietes, formada por trabalhadores, soldados e camponeses.

Tinha em vista as seguintes finalidades:

"Suprimir toda exploração do homem pelo homem, abolir definitivamente a divisão da sociedade em classes, afastar todos os exploradores, realizır a organização socialista da sociedade, e fazer triunfar o socialismo em todos os países".

Por isso estavam de acordo em suprimir toda a propriedade privada, porque todas as terras eram propriedade nacional e como tal deveriam ser entregues aos traba'hadores, sem nenhuma indenização porque resulta em uso para todos, todavia, reservava que todo o solo e subsolo e suas riquezas eram propriedade nacional; tudo o mais era de propriedade do Estado, sendo o trabalho obrigatório para todos, como um dever social.

Essa declaração dos Direitos do Povo Traba!hador e Explorado, como assinaram os doutrinadores, é o documento mais completo do primeiro período da revolução russa e nele está a parte programática da Constituição de 1918, obtendo enorme e consagradora repercussão, todavia, seus princípios não foram repetidos na Constituição de 1936.

A primeira declaracão elaborada por Lenin não reconhece direitos ou garantias individuais ao individuo, senão o poder de uma classe e a preponderância. do Estado, que é o único titular de direitos.

Mirkine Guetzevitch. em "La théorie Generale de L'Etat Sovietique" (Paris, 1928, págs. 9'/98), nega a existência de direitos pessoais inalienáveis e inatos, rechaçando assim a teoria indiviciualista.

Citando a R. Malitzky, afirma que só o Estado é fonte

"dos direitos pessoais dos indivíduos, o Estado só é forte e força criadcra da legislação inteira, porque ele só cria o direito chamado objetivo, somo o conjunto de normas que regem a sociedade". 
Depreende-se assim que o sujeito do poder, sua fonte, como também o fundamento do Direito é o Estado e não o indivíduo.

A primeira Constituição Soviética, também denominada de Constituição da Ditadura do Proletariado, de 1918, tinha na parte doutrinária como fonte, a primeira Declaração de Direitos; já a de 1923 acrescentou a federalização dos estados confederados, e a terceira, a Constituição de 1925 , em seu artigo $1 .^{\circ}$, na parte fundamental, acentuava os princípios contidos na Declaração dos Direitos do Povo Trabalhador e Explorado, aprovada no $3 .^{\circ}$ Congresso Pan-russo e também na Declaração dos Direitos dos Povos da Rússia, de 02 de novembro de 1917.

Em 25 de novembro de 1936, o 8. ${ }^{\circ}$ Congresso dos Sovietes aprovou a $4{ }^{a}$ Constituição sob a direta inspiração de Josef Stalin, e onde se estabelecem princípios básicos sobre eleição dos deputa. dos soviéticos, fixando o direito de indicar representantes às associações de trabalhadores, organizações cooperativas, sociedades culturais ou de jovens, e quebrando a rigidez admite a propriedade de bens pessoais provenientes do trabalho desenvolvido pela pessoa.

Surpreendentemente consigna pela primeira vez direitos e garantias individuais tal qual um estado constitucional do Ocidente, excepcionando-se que tais garantias ficam adstritas à suprema conveniência do Estado; estabelece o regime do partido único para a vida política, e não adere ao regime de repartição dos poderes como se faz traciicionalmente.

O Estado Russo ficou sempre sob a atmosfera da guerra e assim suportou as duas grandes catástrofes que se abateram sobre a humanidade, o que faz surgir no seu povo uma espécie de nacionalismo interno que aplacando os ânimos tornou mais fácil a transição do velho regime feudal dos czares, até o comunismo de hoje.

É de se acentuar, por outro lado, que naquela época, 1917, predominaram os estudos político-sociais, sendo prova disso a Constituição Alemã de Weimar, de 1919, como também já o fizeram a Constituição Mexicana de 1917, que proclamavam a compatibilidade de um estado voltado para o social, sem desprezo do individual, buscando atender um interesse das massas, particularmente dos menos favorecidos pela fortuna.

Mesmo após o brutal retrocesso representado pelos Executivos fortes que dominaram grande parte da história, com Hitler e o nazismo, Mussolini e o fascismo, Franco na Espanha e Salazar em Portugal, e a maneira despótica do governo đos estados árabes, é forçoso reconhecer que o constitucionalismo, contido nas Declarações, ainda tem muito terreno para avançar, o que só faz evidenciar a perpetuidade das declarações francesa e americana, com 
o tempero social advindo do movimento re Lenin e as idéias de Karl Marx.

Analisando o pensamento do notável comparatista que foi Boris Mirkini-Guetzévitch, o brasileiro José Augusto, no prefácio da tradução brasileira do livro daquele mestre, "Evolução Constitucional Européia" (pág. 7), mostra as tendências modernas das tendências predominantes dizendo:

"E impossível hoje opor o político ao social, o ideal indi-
vidualista ao ideal coletivista puro. O coletivismo não é
mais uma doutrina própria aos socialistas somente. A de-
mocracia é coletivista, porque nossa época o é porque na
vida das nações modernas o individlial e o coletivo coe-
xistem. Um verdadeiro liberal moderno admitirá as limi-
tações da propriedade e o controle social tão bem como
o socialista". (pág. 7)

Mesmo para o notável comparatista, russo de nascimento, mas emigrante por convicção, que residiu na França e nos Estados̃ Uniōos, as "democracias populares" fizeram tão somente predominar o caráter social sobre o individual, mas ambas apresentam pontos de vista que modernamente são conciliáveis.

Essa tendência é anotada com muita precisão pelo nosso ilustre professor Pinto Ferreira, quando preleciona.

"De feito, a Inglaterra criou a técnica da monarquia parlamentar, os EUA imaginaram a república presidencial e federativa, a França modelou a república parlamentar, a Alemanha de Weimar a democracia social e a república presidencial-parlamentar, e enfim, a URSS configurou a contextura do socialismo proletário e da planificação estatal, em moldes individuais e característicos, cada um deles com sua zona de influência". (op. cit., págs. 105/ 106, Vol. 1).

\section{CONCLUSÃO}

Outras declarações surgiram até o advento da própria .leclaração promovida pela O.N.U., mas preferimos ficar apenas nas profundamente analisadas, para concluir que nos dias atuais, novamente nos encontramos debruçados sobre o estudo dos direitos da pessoa humana e das funções sociais do Estado Moderno, kuscando uma fórmula que permita ao homem expandir-se, embora na era das armas nucleares a paz universal ainda seja uma quimera. 
Como estudiosos ouvimos ainda uma ponderação final que Pinto Ferreira adiciona com muita propriedade:

“... os frutos previsíveis desse constitucionalismo moderno permitem a esperança alvissareira de um socialismo parlamentar que deverá ser grande obra política, social e jurídica do Estado Moderno, na segunda metade do século XX" (pág. 107).

Esta meta buscada por todos, reflete ainda, que os ideais estabelecidos nas declarações, mesmo inseridas nas diversas Constituições, ainda representam um sonho humano a ser atingido. 


\section{BIBLIOGRAFIA}

01: BOUTMY; E. La declaration des droits de l'homme et du cytoien et M. Jellineck. Anales des Sciences Politiques. Paris, 1902, págs. 415/443.

02. CAETANO, Marcelo: Direito Constitucional. Vol. I, Forense, Rio de Janeiro, 1977.

03. DALLARI, Dalmo de Abreu. Elementos de Teoria Geral do Estado. São Paulo, Saraıva, 1972, págs. 180/182.

04. DI RUFFIA, Paolo Biscaretti. Lo Stato Democratico Moderno nella Legislazione Constitucionalle. Milão, 1946, págs. 655/665.

05. FERREIRA FILHO, Manoel Gonçalves - GRINOVER, Ada Pellegrini - FERRAZ, Anna Candida da Cunha. Liberdades Públicas (parte geral). São Paulo, Saraiva, 1978 (Textos integrais das Declarações de Virgina, Francesa de 1789 e Russa de 1918).

06. FERREIRA FILHO, Manoel Gonçalves. Curso de Direito Constitucional. São Paulo, Saraiva, 1976, págs. 81/82.

07. FERREIRA FILHO, Manoel Gonçalves. O Poder Constituinte. São Paulo, Saraiva, 2. ed., 1985.

08. FERREIRA FILHO, Manoel Gonçalves. Artigo: A Revisão da Doutrina Democrática. Publicado na Revista NOMOS dos Cursos de Mestrado - Bahia, Ceará e Pernambuco. Vol. 4, número 1/2, 1982, págs. 62/86.

09. GETTEL, Raymond G. História das Idéias Políticas, apud QUINTANA, op. cit.

10. HAURIOU, M. Princípios de Derecho Público y Constitucional, apud. QUINTANA, op. cit.

11. JELLINECK, G. Tecria General del Estado, pág. 426, apud QUINTANA, op. cit.

12. MIRKINE-GUETZEVITCH, Boris. Evolução Constitucional Européia, (original francês, versão brasileira). J. Konfino Editor, Rio de Janeiro, 1957.

13. PINTO FERREIRA, Luis Princípios Gerais do Direito Constitucional Moderno. 5.' ed., Revista dos Tribunais, São Paulo, 1971.

14. QUINTANA, Segundo V. Linares. Tratado de la Ciencia Del Derecho Constitucicnal (argentino e comparado). Editorial Alfa, Buenos Aires-Argentina, 1953.

15. SCHMITT, Carl. Teoria de la Constitucion. Editorial Revista de Derecho Privado, Madri - Espanha (s.d., s.ed.)

16. VIAMONTE, Carlos Sanchez. A Revolução Norte-amøricana e a Revolução Francesa, apud op. cit. QUINTANA.

17. VIAMONTE, Carlos Sanchez. El Constitucionalismo. Editorial Bibliográfico. Argentina, Buenos Aires - Argentina (s.d., ed.) 